\title{
Correlation between students' workload and attendance as related towards final grades: A case of study on Statistics for first- year Engineering students
}

\section{Carlos de la Calle Arroyo, Licesio J. Rodríguez-Aragón}

Departamento de Matemáticas, Instituto de Matemática Aplicada a la Ciencia y la Ingeniería, Escuela de Ingeniería Industrial y Aeroespacial de Toledo, Universidad de Castilla-La Mancha, Spain.

\begin{abstract}
Are students' workload and attendance related to final grades? In this work, a monitoring experience of student workload and attendance is presented. During four academic years, first-year students of the Engineering School of Toledo (Universidad de Castilla-La Mancha, UCLM, Spain) have been asked, three times a week, to estimate their autonomous workload devoted to the Statistics subject. The monitoring strategy has been anonymous, open and voluntary and has shown a high ratio of participation: 407 students out of 433. This information has been combined with attending to classroom-based lectures records and final grades. Along this work nonparametric tests haven been used. The concept of "average student" is widely questioned in the literature and therefore instead of comparing mean values comparisons between the distributions are preferred. Results indicate that declared student's workload hardly reaches the 90 hours of autonomous work established in the ECTS ratio of the university. The strong significant differences between the distributions of percentage of attendance for different grading groups as well as the significant differences between the distribution of the percentage of workload monitorization show that attending and participating in the classroom-based lectures has a positive influence on grades.
\end{abstract}

Keywords: workload, attendance, first-year, ECTS, engineering. 


\section{Introduction}

Since the implementation of the Bologna Process and the European Credit Transfer System (ECTS), European Commision (2015), the estimation of the students' workload has been approached by countless works (Pogacnik et al., 2004; Molina et al., 2007; Cañas Belmar \& García Escamilla, 2012; Ceballos Aranda et al., 2015; García Martín \& García-León, 2017; Souto-Iglesias \& Baeza-Romero, 2018). Standards in higher education systems establish that a full-time student needs to complete 60 ECTS per academic year, about 1500 to 1800 hours of work. This leads to the equivalence of 25-30 hours per ECTS. Then each university has different ratios between classroom-based teaching and autonomous study.

A ratio of $40-60 \%$ for presential-autonomous work has been established by the university. Therefore, a 6 ECTS subject requires 150 hours of work, divided into 60 hours of classroombased lectures and 90 hours of autonomous work ( 1 ECTS $=25$ hours). A 6 ECTS subject is usually designed to be taught in a semester and scheduled on 15 weeks, that are slightly affected by local holydays scattered along the semester.

For the teacher, designing a subject implies to arrange these 150 hours of work and then teach 60 hours of classroom-based lectures along these 15 weeks. These hours include theoretical lectures, laboratory and tutoring sessions and include exams sessions. Then each student should organize himself to arrange 90 hours of autonomous work into his workday (Rivadeneyra Sicila, 2015).

Classroom-based lectures are easily recorded on the teacher's schedule, but estimating the workload of autonomous work of each student is an open problem that has been widely addressed (Andreu Martí, 2014).

On the other hand, attendance to classroom-based lectures, especially on first year students, has a noticeable effect on study success (Bevitt et al., 2010; Bijsmans \& Schakel, 2018). Attendance is usually non compulsory and its monitorization is usually seen as a surveilling strategy.

\section{Methodology}

During four academic years: 2015/16-2018/19 all the students enrolled in the first year subject Statistics (6 ECTS, second semester), have been offered to participate in a monitoring study in order to estimate students' workload (433 students). The study was presented in the very first classroom-based lecture and the information has been shared with the students through the online teaching platform following an open data strategy.

At each theoretical lecture (three times a week), the student has been asked to voluntarily answer the question: "Since the last time that you answered to this questionnaire: How many 
hours of autonomous work have you devoted to the subject?". This question has been answered on a paper sheet that is handed to the students at the beginning of the theoretical lecture and collected at the end. On the paper sheet they can find their three last characters of their identity card (this is enough to identify uniquely each student) and an empty cell for the answer. This strategy allows a continuous and anonymous process of data collection. In order to stimulate their participation in the study, the full data are weekly updated on the online teaching platform. Each student can then check the amount of workload declared and compare himself with their classmates. This strategy has achieved a high participation ratio, only 26 students (from the 433) refused participating in the study at all. Table 1 shows how the 407 students that participated in the study are distributed.

Table 1. Distribution of the students by academic year, sex and grade.

\begin{tabular}{|c|c|c|c|c|c|c|}
\hline & \begin{tabular}{l} 
Sex\} $\\
{\text { Grade }}$ & No performance & Fail & Pass & With merit & Sum \\
\hline \multirow[t]{3}{*}{$15 / 16$} & male & 12 & 21 & 23 & 18 & 74 \\
\hline & female & 4 & 4 & 5 & 3 & 16 \\
\hline & Sum & 16 & 25 & 28 & 21 & 90 \\
\hline \multirow[t]{3}{*}{$16 / 17$} & male & 17 & 23 & 31 & 22 & 93 \\
\hline & female & 0 & 7 & 4 & 4 & 15 \\
\hline & Sum & 17 & 30 & 35 & 26 & 108 \\
\hline \multirow[t]{3}{*}{ 17/18 } & male & 17 & 28 & 31 & 16 & 92 \\
\hline & female & 1 & 0 & 4 & 3 & 8 \\
\hline & Sum & 18 & 28 & 35 & 19 & 100 \\
\hline \multirow[t]{3}{*}{ 18/19 } & male & 23 & 29 & 32 & 13 & 97 \\
\hline & female & 3 & 2 & 4 & 3 & 12 \\
\hline & Sum & 26 & 31 & 36 & 16 & 109 \\
\hline \multirow[t]{3}{*}{ Sum } & male & 69 & 101 & 117 & 69 & 356 \\
\hline & female & 8 & 13 & 17 & 13 & 51 \\
\hline & Sum & 77 & 114 & 134 & 82 & 407 \\
\hline
\end{tabular}
\end{tabular}

At the beginning of the final exam the monitoring paper sheet was also handed out for the students to declare the amount of autonomous work since the classroom-based lectures ended. Therefore, the students were asked to estimate their workload almost continuously along the semester. 
On the other hand, attendance was monitored with the help of the Bologna continuous assessment strategy. At the end of each theoretical classroom-based lecture a grading question was offered to the students through the online teaching platform. Also, at each laboratory classroom-based lecture grading questionnaires were offered. Only those that attended the classroom-based lectures could answer these questions. Classroom-based lectures grading had a $20 \%$ weight on the final subject grade.

The numerical final grade, ranging from 0-10, has been categorized in: "Fail" for grades under 5, "Pass" for grades greater or equal than 5 and lower than 7, and "With merit" for grades greater or equal than 7 . Those that didn't attend to a minum of evaluation events have been categorized as "No performance".

\section{Results}

The mean attendance of the 407 students to the classroom-based lectures is of $76.3 \%$ while the mean participation in the workload monitorization is of $67.9 \%$. This is a measure of how the students are involved within the workload monitorization. Students have been encouraged to understand the differences between a missing data and " 0 hours" of autonomous work in the workload monitorization. Obviously, higher attendance implies higher workload declared: there exists a strong linear correlation between them, Pearson correlation coefficient is significant and up to 0.89 .

Students that have attended to a percentage of classroom-based lectures greater than the mean (76.3\%) and participated in the workload monitorization less than the mean $(67.9 \%)$ have been identified: 24 out of 407 . These students seem to drop from the monitorization while keep attending the classroom-based lectures. After analyzing these records, neither gender nor grade differences explain this behavior.

To try to answer the question: “Are students' workload and attendance related to final grades?" nonparametric tests have been performed to detect significant differences between percentage of workload declared or grading categories. Nonparametric tests compare the distributions instead of comparing means and this is suitable for this situation were the concept of "average student" is widely questioned in the literature (García Martín \& GarcíaLeón, 2017). 


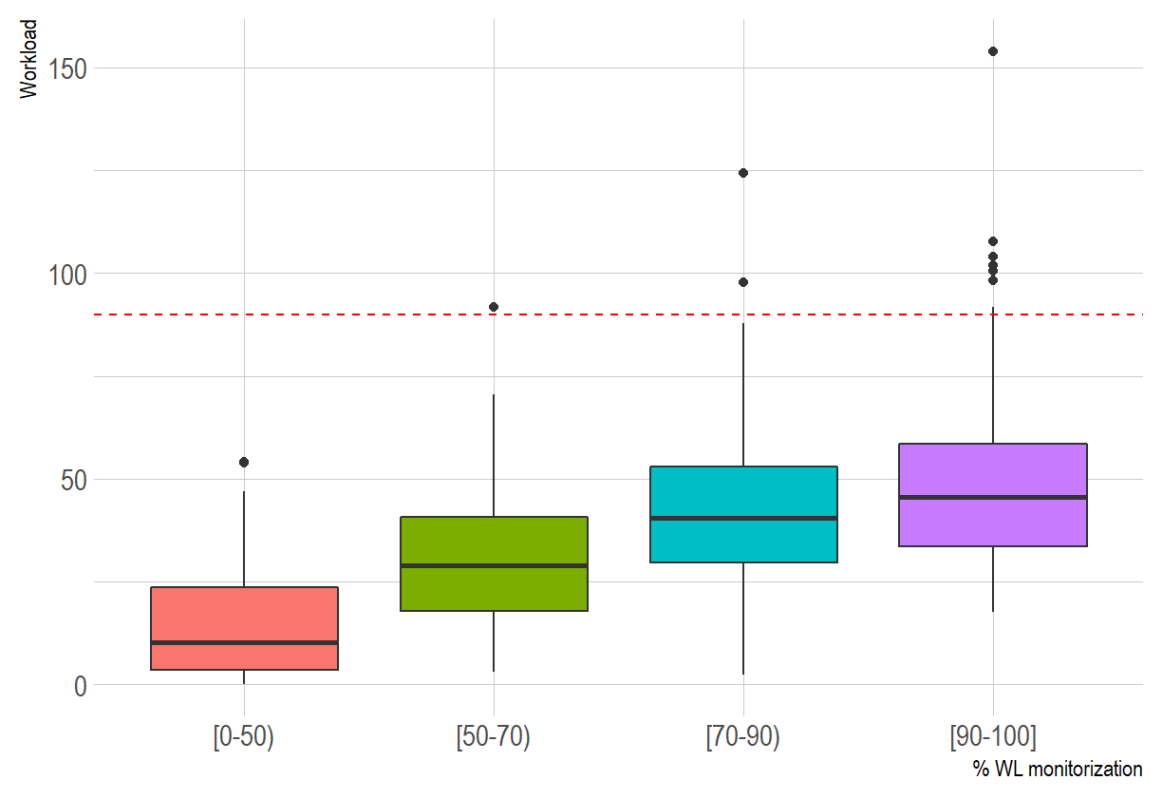

Figure 1 Workload vs. Percentage of Workload Monitorization.

Firstly, whether the students achieve the 90 hours of expected autonomous work is checked. Figure 1 shows the distribution of autonomous workload declared by the students for different percentages of workload monitorization. The 90 hours are only exceeded by 10 students. And the mean workload out of the 407 students is of 35.6 hours. Mean value should be taken with caution due to the great dispersion of the number of autonomous hours declared, ranging from 0 to more than 150 hours.

The percentage of workload monitored, \%WL, has been discretized into four groups, Table 2 shows the workload for each of these groups. The first category $[0,50)$ are students that filled the monitoring paper sheet in less than half of the occasions while the last category $[90,100]$ are students that did it in almost all the occasions: filling the monitoring sheet was voluntary. 
Table 2: Workload declared for the four groups of percentage of workload monitored, \%WL.

\begin{tabular}{rccccccc}
\hline \multicolumn{7}{c}{ Workload declared in hours: } \\
\% WL & Min. & 1stQu. & Median & Mean & 3rdQu. & Max & N \\
\hline$[\mathbf{0 - 5 0 )}$ & 0.0 & 3.5 & 10.3 & $\mathbf{1 4 . 7}$ & 23.5 & 54.0 & $\mathbf{9 9}$ \\
{$[\mathbf{5 0 - 7 0 )}$} & 2.9 & 17.9 & 28.9 & $\mathbf{3 1 . 0}$ & 40.6 & 91.7 & $\mathbf{6 4}$ \\
{$[\mathbf{7 0 - 9 0 )}$} & 2.3 & 29.6 & 40.5 & $\mathbf{4 2 . 3}$ & 52.9 & 124.3 & $\mathbf{1 3 4}$ \\
{$[\mathbf{9 0 - 1 0 0 )}$} & 17.7 & 33.6 & 45.4 & $\mathbf{4 9 . 1}$ & 58.6 & 154.0 & $\mathbf{1 1 0}$ \\
\hline
\end{tabular}

A Kruskal-Wallis test has been performed to compare the distribution of workload between these four groups, the test rejects the null hypothesis of equally distributed workloads for the four groups ( $\mathrm{p}$-value $=0$ ). Then the Dunn test, with Bonferroni correction, of multiple pairwise comparisons finds significant differences between all the comparison except for the [70\%-90\%) and [90\%-100\%] (p-value $=0.39)$. All the significant differences between the distribution of workload declared by the students in each group are quite strong, all of them with p-values less than $\alpha=0.01$.

In a second stage, a comparison between percentage of workload monitored, \%WL, and the grade achieved by the student has been performed. Figure 2 shows the distribution of grade achieved in the subject (in numerical scale 0-10) for different percentages of workload monitorization. Graphically it can observed that those students that have been monitored at most of the classroom-based lectures tend to obtain higher grades.

The Kruskal-Wallis test rejects the equally distributed null hypothesis and therefore finds significant differences between at least two \%WL groups ( $\mathrm{p}$-value $=0)$. The multiple comparisons performed by the Dunn test, with Bonferroni correction, show that all the comparisons are significant except for [0\%-50\%) and [50\%-70\%) (p-value $=0.51$ ). Again, all the significant differences between the distribution of grades achieved by the students in each group are quite strong, even for significance levels less than $\alpha=0.01$. Mean values of workload for each \%WL group are highlighted in Table 2. 


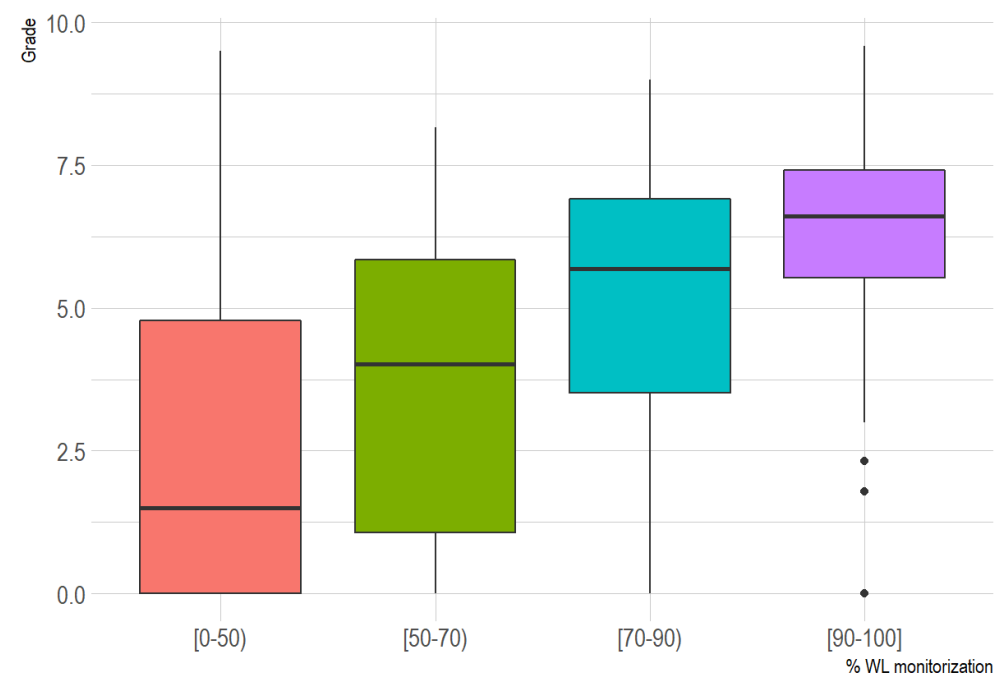

Figure 2. Grade vs Percentage of Workload Monitorization.

Finally, the distribution of percentage of attendance to classroom-based lectures between the four grading groups have been compared (Figure 3). Graphically it can be seen that students with higher grades tend to attend to higher percentages of classroom-based lectures.

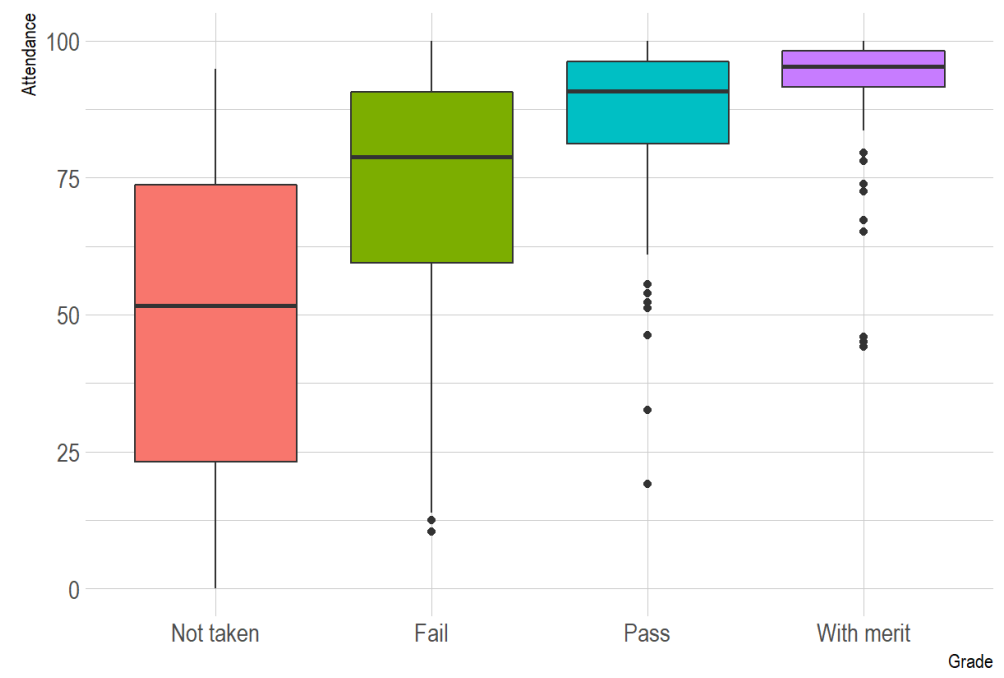

Figure 3. Attendance vs Grade. 
The Kruskal-Wallis test finds significant differences and rejects the equally distributed null hypothesis ( $\mathrm{p}$-value $=0$ ). The Dunn test, with Bonferroni correction, of multiple pairwise comparison finds strong significant differences between all the comparisons, all of them with p-values less than $\alpha=0.01$.

Table 3 shows the percentage of attendance for each of the grading groups, mean percentage of attendance is highlighted. Again, large dispersion is observed and the concept of "average student" is questioned. This is the main reason why nonparametric tests have been used to compare distributions instead of comparing means.

Table 3: Percentage of attendance for the four grading groups.

\begin{tabular}{cccccccc}
\hline Grade & Min. & 1stQu. & Median & Mean & 3rdQu. & Max & N \\
\hline No Performance & 0 & 23 & 52 & $\mathbf{4 8}$ & 74 & 95 & $\mathbf{7 7}$ \\
Fail & 10 & 59 & 79 & $\mathbf{7 2}$ & 91 & 100 & $\mathbf{1 1 4}$ \\
Pass & 19 & 81 & 91 & $\mathbf{8 6}$ & 96 & 100 & $\mathbf{1 3 4}$ \\
With merit & 44 & 92 & 95 & $\mathbf{9 2}$ & 98 & 100 & $\mathbf{8 2}$ \\
\hline
\end{tabular}

\section{Discussion and Conclusions}

In order to find an answer to the initial question: “Are students' workload and attendance related to final grades?" the strategy of paper handout and daily monitorization of students' autonomous work has proved itself as a useful tool to estimate students' workload. The participation of 407 out of 433 students and the strong correlation between workload monitorization and attendance are proofs of it.

The fact that the declared students' workload hardly reaches the 90 hours of autonomous work established in the ECTS ratio of the UCLM is widely shared in the literature (Pogacnik et al., 2004; Molina et al., 2007; Cañas Belmar \& García Escamilla, 2012; Ceballos Aranda et al., 2015; Rivadeneyra Sicila, 2015; Souto-Iglesias \& Baeza-Romero, 2018). This experience shows proofs of an overestimation of nominal hours for each ECTS credit and these are more than enough evidences urging to reconsider, after more than 10 years of ECTS experiences, realistic and desirable schedules for students. Also notice that large differences usually appear between different subjects that are being taught at the same time.

It is striking to compare over Table 2 the disjoint interquartile ranges (Q1-Q3) of workload for those with less than $50 \%$ and those with $90-100 \%$ of workload monitorized: $3.5-23.5$ vs. 33.6-58.6 hours. Also, disjoint interquartile ranges are found on Table 3 while comparing percentages of attendance for those that "Failed" or passed the subject "With merit": $59-91 \%$ vs. $92-98 \%$. Nonparametric statistical procedures in this work have only been used to 
quantify, in terms of probability, differences that graphs and tables clearly show. The strong significant differences between the distributions of percentage of attendance for the grading groups as well as the significant differences between the distribution of the percentage of workload monitorization show that attending and participating in the classroom-based lectures has a positive influence on grades.

\section{Acknowledgements}

We would like to thank the selfless collaboration of our students as well as their always constructive criticism.

\section{References}

Andreu Martí, M. M. et al. (2014). ¿Es posible cuantificar la carga de trabajo real de un "estudiante medio" de forma fiable? II Congreso Internacional de Innovación Docente. Retrieved from: http://repositorio.upct.es/bitstream/handle/10317/3956/c002_2014.pdf

Bijsmans, P. \& Schakel, A.H. (2018) The impact of attendance on first-year study success in problem-based learning. High Educ, 76(5), 865-881. doi: 10.1007/s10734-018-0243-4

Bevitt, D., Baldwin, C. \& Calvert, J. (2010) Intervening Early: Attendance and Performance Monitoring as a Trigger for First Year Support in the Biosciences. Bioscience Education, 15(1), 1-14. doi: 10.3108/beej.15.4

Cañas Belmar M. P. \& García Escamilla E. (2012) Carga de trabajo autónomo del estudiante: tiempo de dedicación real y estimación de los docentes. X Jornadas Redes de Investigación en Docencia Universitaria. 246836. Retrieved from: https://web.ua.es/es/ice/jornadas-redes-2012/documentos/comunicacionesorales/246836.pdf

Ceballos Aranda M., Vílchez López J. E. \& Escobar Benavides T. (2015) Carga de trabajo autónomo estimada por el estudiante de Magisterio en asignaturas de ciencias. Exploración de su relación con el rendimiento académico. Escuela abierta: revista de Investigación Educativa, 18, 55-73. doi: 10.29257/ea18.2015.04

European Commision (2015). ECTS Users' Guide. doi:10.2766/87592

García Martín, A. \& García-León, J. (2017) Una experiencia de medición de la carga de trabajo percibida por los estudiantes para facilitar la coordinación horizontal. REDU. Revista de Docencia Universitaria, 15(1), 81-104. doi: 10.4995/redu.2017.5987.

Molina, A., Terrasa, A., Vendrell \& E., Sanchís, E. (2007) ECTS evaluation in the Faculty of Computer Science of the Polytechnic University of Valencia. International Conference on Engineering Education - ICEE 2007. Retrieved from http://www.ineer.org/Events/ICEE2007/papers/303.pdf

Pogacnik, M., Juznic, P., Kosorok-Drobnic, M., Pogacnik, A., Cestnik, V., Kogovsek, J., Pestevsek, U. \& Fernandes, T. (2004) An attempt to estimate students' workload. J. Vet. Med. Educ., 31(3),255-60. doi: 10.3138/jvme.31.3.255. 
Souto-Iglesias, A. \& Baeza-Romero M. T. (2018) A probabilistic approach to student workload: empirical distributions and ECTS. High Educ, 76, 1007-1025. doi: 10.1007/s10734-018-0244-3

Rivadeneyra Sicila, J. M. (2015). Créditos ECTS: normativa y realidad. Actas de las XXI Jornadas de la Enseñanza Universitaria de la Informática, 26-33. 